Having originally researched the activities of the potent hematopeotic stimulator of bone-marrow cells, granulocyte colony stimulating factor, Shigekazu Nagata is better known for his work on apoptosis. Here, one of Japan's most renowned biomedical scientists outlines the path that has taken him full circle: from stimulating cells to grow, to finding out how they die, to tying the two processes together.

For a man who spends most of his time thinking about death, Shigekazu Nagata is remarkably upbeat. For over a decade, he has been making a name for himself with research on apoptosis, the mechanism of programmed cell death, and during that time he has watched the field come alive. "Medline publications on apoptosis have risen from only a couple of hundred in 1990 to over 10,000 this year," he says with a satisfied nod.

Nagata spoke to me in his office at Osaka University, where he has been a professor in the Department of Genetics for five years. "Apoptosis is fun. It's like fireworks," he says, pointing to a screen full of magnified cells that bulge, contract, fragment and change colors, before shrinking and disappearing into oblivion.

He is credited with elucidating some of the basic cellular machinery that propels the process of apoptosis, such as the cellsurface receptor, Fas. Early work with his colleague at the Osaka Bioscience Institute (OBI), Shin Yonehara, who had shown that a mouse antibody to Fas was involved in the cytolytic pathway, revealed that the antibody worked as an agonist; that is, that it contributed actively to the death of the cell rather than merely blocking proliferation. Nagata further characterized the function of Fas by showing that mice with a mutation in this receptor develop lymphoproliferation, a condition in which lymph cells lose the ability to undergo apoptosis and accumulate.

The next step was to discover exactly how Fas caused apoptosis in natural, nonstimulated conditions. During this period of investigation, Nagata received a fax from Pierre Golstein at France's CNR's "cytotoxic T-cell with Fas-specific properties," asking him whether he was interested in a collaboration. "Of course I was interested!" he remembers. Together they set about cloning and characterizing the Fas ligand.

Nagata has since migrated from this ligand-receptor surface interaction to study cell death from inside the cell, and has continued to do groundbreaking work characterizing proteins that promote apoptosis. In 1998 he published his discovery of a novel DNase and its inhibitor, ICAD, which is ex-

\title{
Shigekazu Nagata
}

clusively activated in apoptosis. He says there are several questions left to be answered concerning the Fas pathway. Central among them is, how does the oncogene product $\mathrm{Bcl}-2$ block apoptosis? However, he has no personal plans to work on an answer to that question, perhaps because he has become a victim of his own success at propagating interest in cell death. "There are so many other good researchers working on this, I'll leave it to them."

Apoptosis is an area of basic research filled with promise of therapeutic application. Where cell death leads to disease, such as in hepatitis or Alzheimer disease, the apoptotic pathway could be blocked. When cancerous cells are proliferating uncontrollably, the apoptotic sys-

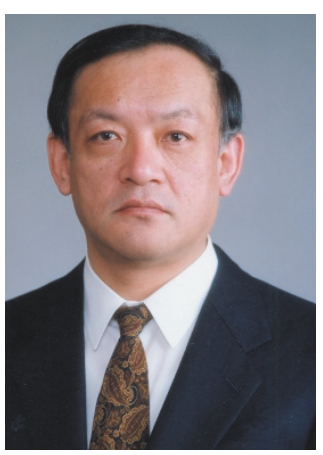

Shigekazu Nagata
Charles Weissmann. He took the job because at that time, "almost no one was using recombinant DNA technology in Japan." He credits his experience in Weissman's lab with forming the basis for his future studies and teaching him an "orderliness and logical procedure" to research. In 1982, he returned to IMS for a short time before moving to the OBI in 1987 and then to taking up his current position at Osaka University. He encourages this kind of mobility, which is quite unusual in Japan where researchers often remain at their alma mater for most of their career.

Nagata is also unusual in his eschewal of the institute directorships and administrative positions that usually come with senior research positions in Japan. "If you're the tem could be activated. Nagata, however, says he has little interest in trying his hand at more applied studies within a biotechnology company. In fact, Japanese scientists are often criticized for their lack of interest in applied researchgiving rise to Japan's stumbling efforts to promote biotech. But Nagata says the reason he and his peers are reluctant to take part in commercial ventures is because private investment is insufficient. "The government is the one that is pouring money into biotech, but it's a huge gamble. Even in the United States, $90 \%$ of companies fail. I don't want to gamble with the taxpayer's money."

This doesn't mean that others haven't picked up on the value of Nagata's research. Mochida Pharmaceuticals, for one, has licensed a patent from OBI, where Nagata did much of his Fas research, for use of the Fas ligand system in developing clinical treatments.

What sets Nagata apart from most Japanese researchers is his willingness to move between different laboratories. After receiving a PhD from Tokyo University's Institute of Medical Sciences (IMS) in 1977, he traveled to Zurich, Switzerland, where he worked on cloning the gene encoding interferon- $\alpha$ in the laboratory of boss, you can't be productive anymore," he laughs. That said, he currently holds the post of director of the Japanese Biochemical Society. "No one ever turns [the Biochemical Society] down," he admits.

Present efforts outside of apoptosis research are directed at establishing a 'nanobiology' graduate program at the University. "This is re-construction of the Institute of Molecular and Cellular Biology that was established here 20 years ago. Several professors from the Medical School and the Department of Engineering Science would join together in an effort to apply nanotechnology to medicine," he explains.

In the meantime, Nagata is taking his apoptosis research in new directions. He's investigating parallels between apoptosis and hemopoesis. "When a macrophage recognizes a cell undergoing apoptosis, it separates and fragments the nuclei. Similarly, during differentiation, precursors to red blood cells undergo enucleation, by which their nuclei are transferred to macrophages where they are consumed. There must be parallels in how the macrophage is able to recognize and take out the nucleus in these two processes," enthuses Nagata.

David Cyranoski, Tokyo 